\title{
Assessment of Health-Related Quality of Life (HRQoL) by EQ-5D in Prediabetes, Diabetes and Normal Glycaemic Population in China
}

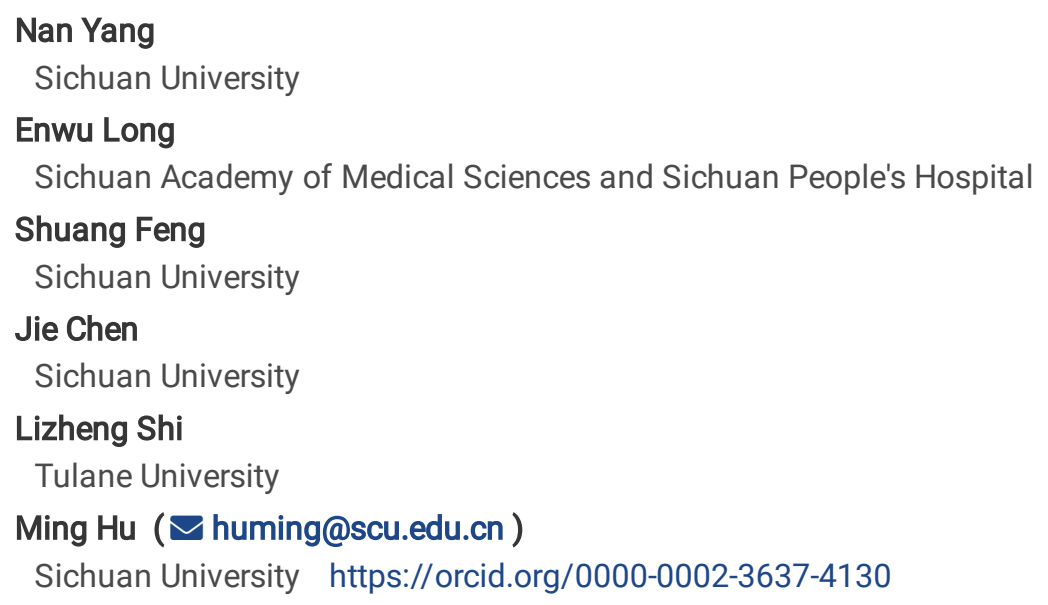




\section{Abstract}

Aim of the study was to describe and compare differences of health-related quality of life (HRQoL) among populations of normal glycaemic, pre-diabetics and diabetics in China.Methods A quality of life survey based on the EQ-5D-5L scale was conducted through face-to-face interviews and telephone follow-up. A total of 403 respondents with diabetes, 404 respondents with pre-diabetes, and 398 respondents with normal blood glucose were enrolled in the survey. Differences among groups were compared by chi-square test oneway analysis of variance (ANOVA), Kruskal-Wallis test or student's test after adjusting parameters of age and gender by PSM and Covariance analysis. Results In this survey, most of the diabetics were associated with circulatory system or nutritional metabolic diseases. The EQ-5D index of normal glycaemic population, pre-diabetic, and diabetic patients was $0.901,0.948$, and 0.897 . And EQVAS scores of every groups above were $73.76,77.45$, and 68.34 . HRQoL of male was higher than female in three groups of the study. In general, blood sugar control of Chinese diabetics was generally well. Results of covariance analysis and PSM were consistent with above results.Conclusion There was a general trend that patients was associated with a decline of HRQoL from pre-diabetic population, normal glycaemic population to diabetics. However, further and larger longitudinal studies are needed to confirm these findings.

\section{Background}

Diabetes is one of the most popular and serious chronic diseases in the world. It's estimated 422 million adults were living with diabetes worldwide in 2014, which would rise to 642 million by $2040^{[1]}$. People diagnosed of diabetes should take medications or insulin injections all their lives. According to the statistics of International Diabetes Federation(IDF), average cost of diabetes treatment and illness management was about $\$ 1,622$ to $\$ 2,886$ per diabetic in 2015 . The direct medical cost of diabetes in China is $\$ 466$ per person, which brings great burden to the patient and their family. At the same time, diabetes are also the important factors causing a variety of complications, such as cardiovascular, eye, kidney and nervous system diseases. Serious complications can even lead to heart attack, stroke, blindness, renal failure, disability and even death. Globally, the number of people died of diabetes increased to 5 million in 2015, which was more than entire number of people dying from HIV/AIDS, tuberculosis and malaria in $2013^{[1]}$. Thus, diabetics must bear physical and mental burden, which have severe, great and long-term impact on the Health-Related Quality of Life (HRQoL) of them. And several studies using EuroQoL-5 Dimension (EQ-5D) had shown that HRQoL of patients with type 2 diabetes (T2DM) report significantly lower than the normal glycaemic population ${ }^{[2-4]}$.

Prediabetes defined as glycaemic variables are higher than normal and lower than diabetes thresholds, which is a transition from normal glucose tolerance(NGT) to diabetes mellitus(DM), indicating the relatively high risk for the future development of diabetes ${ }^{[5]}$. Without timely intervention, pre-diabetics are easily to progress to diabetes in ten years, or sooner ${ }^{[6]}$. Statistics suggest that the prevalence of prediabetes is approximately $25 \%$ among adults aged 45 years and older ${ }^{[7-9]} \llbracket 5 \%$ to $10 \%$ people with prediabetes will progress to diabetes every year ${ }^{[10]}$. A study with SF-12 in German showed as blood glucose grew worse, the HRQoL of old people with NGT, prediabetes or diabetes was in the trend of lowing gradually [11].

Now, China has become the country with highest prevalence of diabetes in Asia ${ }^{[12]}$. By 2015, there has been 10.96 million people diagnosed with diabetes in China ${ }^{[1]}$, which would rise to 42.30 million by $2030^{[13]}$. Nowadays, it is estimated that there almost are 493 million prediabetics in China ${ }^{[14]}$. Wang's investigation showed that ${ }^{[12]}$ the prevalence of prediabetes in Chinese adults was $35.7 \%$ according to the diagnostic criteria of the American Diabetes Association(ADA). Zhuang's ${ }^{[15]}$ study indicated that the prevalence of prediabetes was $16.8 \%$ in South China, of which only $38.5 \%$ person were aware of this. The prevalence of prediabetes was $25.13 \%$ in Chengdu, a great city of China, per Ma' study ${ }^{[7]}$. EQ-5D has been used to measure the quality of life in Chinese diabetics in some studies. A survey ${ }^{[17]}$ in East China showed that the quality of life of Chinese patients with diabetes is significantly lower than that of the normal population. However, there has been no study on differences in the quality of life among Chinese population with normal glycemia, prediabetes and diabetes.

Therefore, we compared the quality of life among Chinese population with normal glycemia, prediabetes and diabetes through a crosssectional survey based on EQ-5D-5L questionnaire.

\section{Methods}

\section{Study Population}


The survey was conducted in Sichuan province located in Southwest of China. Sichuan has a population of 82 million, accounting for $5.97 \%$ of the total population of China ${ }^{[18]}$. In 2015 , per-capita GDP of Sichuan was $\$ 5519$ at national average level, ranking twentythird in 31 provinces. In this survey, we selected diabetics from the out-patients who receiving treatment in several tertiary hospitals. Prediabetes population were the people who had physical examination in several tertiary hospitals and conformed inclusion criteria. Normal glycemia people were randomly selected from parks and communities in Sichuan province who met the inclusion criteria.

\section{Inclusion and Exclusion Criteria}

Eligible diabetic population should fulfill following criteria: the people participated voluntarily; over 18 years of age; and could be diagnosed by the physician or by inquiry that they met the ADA diabetes diagnostic criteria ${ }^{[1]}$ : Hemoglobin $\mathrm{A} 1 \mathrm{C}(\mathrm{HbA} 1 \mathrm{C}) \geq 6.5 \%$ or Fasting Plasma Glucose (FPG) $\geq 126 \mathrm{mg} / \mathrm{dL}(7.0 \mathrm{mmol} / \mathrm{L})$ or 2-h plasma glucose $(\mathrm{PG}) \geq 200 \mathrm{mg} / \mathrm{dL}(11.1 \mathrm{mmol} / \mathrm{L})$ during an oral glucose tolerance test (OGTT); or a patient with classic symptoms of hyperglycemia or hyperglycemic crisis, a random plasma glucose $\geq 200$ $\mathrm{mg} / \mathrm{dL}(11.1 \mathrm{mmol} / \mathrm{L})$. We excluded people who had disturbance of consciousness and response (People with hearing loss or tinnitus were also included in the study if they could fill out the questionnaire) or been diagnosed with the gestational diabetes.

Eligible people with pre-diabetes should fulfill following criteria: the people participated voluntarily; over 18 years of age; met the diagnostic criteria for prediabetes published by ADA: FPG between $100 \mathrm{mg} / \mathrm{dL}(5.6 \mathrm{mmol} / \mathrm{L})$ to $125 \mathrm{mg} / \mathrm{dL}(6.9 \mathrm{mmol} / \mathrm{L})$ or $2-\mathrm{h} \mathrm{PG}$ during 75-g OGTT between $140 \mathrm{mg} / \mathrm{dL}(7.8 \mathrm{mmol} / \mathrm{L})$ to $199 \mathrm{mg} / \mathrm{dL}(11.0 \mathrm{mmol} / \mathrm{L})$ (IGT) or $\mathrm{HbA} 1 \mathrm{C}$ between $5.7 \%$ and $6.4 \%$. We excluded people who had disturbance of consciousness and response (People with hearing loss or tinnitus were also included in the study if they could fill out the questionnaire) or been diagnosed with diabetes.

Eligible people with normal glycaemic should fulfill following criteria: the people participated voluntarily; over 18 years of age; normal glycaemia or self-reported without diabetes. We excluded people who had disturbance of consciousness and response (People with hearing loss or tinnitus were also included in the study if they could fill out the questionnaire) or been diagnosed with diabetes and prediabetes.

\section{Sample size and sampling}

According to sample size formula for simple random sampling(SRS) $n=\rrbracket$ enough sample size shall be no less than 384 . Considering $10 \%$ ineffective response rate, we should interview 422 people for each types of blood glucose filling out questionnaires. In this study, we collected 403 effective questionnaires from normal glycaemic people, 404 from prediabetic people and 398 from diabetic people, after removing ineffective questionnaires because of missing main information.

\section{Questionnaire Design}

Questionnaire was tentatively designed based on literatures as well as inviting suggestions from clinical pharmacists and endocrinologists. The questionnaire consisted of six parts including demographic data, disease situation, economic situation, health insurance, living habits and EQ-5D-5L scale. A pilot survey was conducted among 20 interviewees in April 2015, based on which we modified the questionnaire including 6 parts, 22 questions. EQ-5D-5L instrument was applied in this study after registering on www.euroqol.org. EQ-5D-5L scale consists of descriptive system and EQ Visual Analogue scale (EQ-VAS). The descriptive system including five dimensions: mobility, self-care, usual activities, pain/discomfort, anxiety/depression. Each dimension is divided into 5 levels: no problems, slight problems, moderate problems, severe problems, and extreme problems.

\section{Conducting the Survey}

Four trained investigators put the investigation in practice from June 2015 to March 2016. Informed consent was obtained from every respondent before surveyed. Diabetics were interviewed through face-to-face confabulation method when they were waiting to see the doctor in the hospitals. Normal glycaemic people were surveyed face-to-face in parks or communities. For those people, blood sugar 
status was asked firstly to exclude respondents who did not know their blood glucose status or who had diabetes. Questionnaires were completed by the investigators according to the patient's dictation when interviewees were not convenient.

People with pre-diabetes were reached by hospital medical examination centers. Upon approval of the pre-diabetics, surveys were carried on over the phone at the appointed time.

\section{Statistical analysis}

The data from questionnaires was recorded by EpiData version 3.0 (EpiData Association, Odense, Denmark) and processed by EXCEL (2013). Reliability of questionnaire was measured by Cronbach's alpha coefficient(a). The statistical package for social science (SPSS 20, Chicago, IL, USA) software was used for statistical analysis. The parametric test was executed as the data followed normal distribution. And non-parametric tests were selected as the data followed abnormal distribution or doesn't meet the requirements of parametric test. EQ-VAS scores and EQ-Index values were expressed as average $\pm S D(x \pm s)$. The EQ-Index was calculated by Chinese EQ5D-5L set. All statistical tests were bilateral. Testing significance of difference and correlation between variables were analyzed by chisquare test, t-test, one-way analysis of variance (ANOVA) or Kruskal-Wallis test. Analysis of covariance was used to adjust covariates, then quality of life of the three groups after correction were compared. Besides age, sex, BMI, and household income of the three groups were matched by PSM. Statistical analysis based on the data above. Statistical significance was established as $\mathrm{P}<0.05$.

\section{Results}

\section{Socio-demographics}

Cronbach's a of questionnaire about diabetics, pre-diabetics and normal glycaemic population were $0.721,0.748$ and 0.753 respectively and the content validity of was $0.673,0.728$ and 0.840 correspondingly, which showed good reliability and validity of questionnaire.

There were statistical differences in age, BMI, gender, alcohol consumption, education level, type of medical insurance, family income, and family history of diabetes for three groups of respondents from different populations. Socio-demographic features of respondents grouped by glucose status were showed in Table 1.

\section{Blood Glucose status}

We gathered blood glucose data of pre-diabetics and diabetics, which was displayed in Table 2. It should be noted that blood glucose level of diabetics was recorded after drug using. The normal glycemic respondents' glucose level were not recorded, which was unable to be provided accurately. According to Guidelines for Prevention and Treatment of Hypertension in China, the standard for good controlling blood glucose is to keep FPG within 3.9-7.2mmol/L, $2 \mathrm{hPG} \leq 10 \mathrm{mmol} / \mathrm{L}$ and $\mathrm{HbA} 1 \mathrm{c}<7 \%$. Among all the diabetics, rates of under-control for FPG, $2 \mathrm{hPG}$ and $\mathrm{HbA} 1 \mathrm{c}$ were $40.0 \mathrm{0}, 31.03 \%, 40.58 \%$, respectively.

\section{Complication of diabetes}

Investigations have shown that circulatory diseases and nutritional metabolic diseases are the main common complication diseases for the three groups. And the incidence of complications increase with increasing the risk of diabetes. The results showed that occurrence rates in diabetics of circulatory system and nutritional and metabolic diseases were $38.19 \%$ and $31.41 \%$ which were $23.27 \%$ and $22.28 \%$ in pre-diabetics, $25.31 \%$ and $10.42 \%$ in normal glycaemia people respectively. More than half of people with diabetes are accompanied by other diseases in the research, of which hypertension, hyperlipidemia and diabetic retinopathy ranked the first three among all the complications. Details were attached Table 3.

\section{Quality of life measure}


As shown in Table 4, the main health-related problem existing in the respondents with different blood glycaemia status were pain/discomfort, anxiety/depression and self-care which had lowest ranking. The proportion of health-related problems in the five dimensions was consistent among three groups. The sequence of respondents' self-assessments in health-related problem occurrence from high to low was pain/discomfort】anxiety/depression\mobility】usual activities and self-care.

EQ-VAS score and EQ-Index of diabetics, pre-diabetics and normal glycaemic people were shown in Table 5. EQ-VAS scores from high to low were pre-diabetes, normal blood glucose, and diabetes. EQ-Index of the study were calculated by Chinese EQ-5D-5L value sets which was processed by dimension reduction method. Health utility value of diabetics was lower than normal glycaemic people and the pre-diabetes patients have higher health utility values than normal glycaemic people. Among the three blood glucose status groups, the quality of life of women was lower than that of the corresponding male population.

Due to the sample came from different population, we carried out covariance analysis and PSM separately so as to compare the difference in quality of life among three groups. We set age, gender, BMI, alcohol consumption, education situation, medical insurance, household income and family history of diabetes as covariates, then regarding type of different blood-sugar population as independent variable, EQ-5D-5L and EQ-VAS as dependent variable, conducted covariance analysis. When EQ-VAS scores was the independent variable, the pre-analysis showed that there was no significant interaction between the type and the covariates. The results of covariance analysis showed that the degree of education and annual household income were the main variables affecting the score of health utility. Covariance analysis showed that the EQ-VAS of population of normal glycaemic, prediabetes and diabetes were 74.78, 75.49 and 69.35 , and EQ-Index of three groups were $0.910,0.926,0.910$ respectively. At the same time, the propensity score matching (PSM)was used to adjust the age, income, gender by matching two groups firstly, the result of which was matched with the third group. Finally, we got 99 people in every kind of blood glucose status matched. The result of PSM showed that the EQ-VAS of population of normal glycaemic, prediabetes and diabetes were $73.71,75.71$ and 66.20 , and EQ-Index of three groups were $0.866,0.898,0.846$ respectively. Specific results were shown in Table 6.

\section{Discussion}

This study described HRQoL of normal glycemic population, pre-diabetics and diabetics in China. Compared with EQ-VAS scores ranging from 61 to 79 in other EQ-5D surveys, result of the study of Chinese diabetics was 69.35, which was at an intermediate level. Compared with the data from other countries, the EQ-VAS score of Chinese diabetes population is slightly higher than Spanish and Poland patients', which was 61.106 and 68.2 respectively ${ }^{[19-20]}$. The EQ-Index of this study was consistent with Zhou's ${ }^{[21]}$ research which showed EQ-Index value of Chinese diabetic patients ranking from 0.79 to 0.94 , which means result of the study was still in the middle range. Compared with the EQ-Index of Spanish ${ }^{[19]}$ and German ${ }^{[3]}$ diabetes whose score was 0.742 and 0.80 respectively, EQIndex of diabetes in the study was slightly higher. Prevalence of diabetes or prediabetes of male was higher than female in the study, but the differences was not statistically significant. The result of the study was consistent with results of some other studies in which prevalence of diabetes in female is lower than male in Chinese ${ }^{[9,23,24]}$. In the other words, men should pay more attention to their glycaemia status as well as life-style.

According to WHO statistics, there are hundreds of complications in patients with diabetes, such as diarrhea, periodontitis, coronary heart disease, heart rate irregularity, nephropathy, frequency of urination, sexual dysfunction, arteriosclerosis, numbness of hands and feet, constipation, dry skin, glaucoma, cataract, ulcer, cerebral ischemia, retinopathy, gangrene, etc. Literature shows $30 \%$ of chronic renal failure, $40 \%$ to $50 \%$ of blindness, $50 \%$ of cardiovascular and cerebrovascular diseases, and $60 \%$ of amputations are caused by diabetes ${ }^{[25]}$. Our study showed half of diabetics suffered complications, in which $32.25 \%$ diabetics had one kind of complication, $19.50 \%$ diabetics had two kinds of complications, about $11.00 \%$ diabetics had more than three kinds of complications. Among all complications, macroangiopathy and microangiopathy were the main causes of disability or death in elderly diabetics. In this study, atherosclerosis accounted for $0.75 \%$ of diabetic patients with macrovascular disease, and incidence of retinopathy, neuropathy and anemia was $9.25 \%, 4.75 \%$ and $0.5 \%$ respectively. Therefore, diabetic patients should pay more attention to prevent macroangiopathy and microangiopathy, especially atherosclerosis, retinopathy, neuropathy and anemia.

In the survey, $52 \%$ patients had dietary and exercise controlling, but only $14 \%$ patients controlled continuously. Most patients misunderstood the way of controlling diet and exercise. For diet controlling, most patients only avoid oily food, sugar and sweets. They were lacked of awareness in calculating calories in foods and practicing separate eating. Therefor patient education of how to get a good dietary and exercise controlling is necessary. 
From the survey, we observed that the quality of life in prediabetics was higher than that in normal glycemic people and diabetics. This results were different from a previous German survey showing that the quality of life gradually decreased as glycemic status deteriorated ${ }^{[3]}$. This may be due to some design defects in this study. The samples of the study were collected from three different populations. The samples of pre-diabetic group mainly came from people who went to the physical examination centers of tertiary hospitals and had more awareness and capabilities for self-health protection. At the same time, most of them had better jobs and accessed to health insurance easier. In the aspects of family income and education background, they had more advantageous than the diabetics and the normal glycaemic population, who were easier to maintain good physiological and mental state. However, after correcting each parameter of gender, age, BMI, alcohol consumption, family history of diabetes, and type of medical insurance by using covariance analysis, results still showed that the quality of life of pre-diabetic group was better than normal glycaemic population and diabetics. This is probably the result of that asymptomatic pre-diabetic patients have lower rates of anxiety or depression (30.30\%) than other populations.

There were other limitations in this study, such as recall bias of the blood sugar indicator, diet, exercise, sleep and illness acquired by questionnaire. Furthermore, the study was a cross-sectional study that does not directly determine the causal relationship between changes in quality of life and the dynamic evolution of diabetes. And we did not discuss EQ-VAS score of diabetes subgroups due to the large differences of sample size in them.

\section{Conclusion}

There was a general trend that patients were associated with a decline of HRQoL from pre-diabetic population, normal glycaemic population to diabetics. However, further and larger longitudinal studies are needed to confirm these findings.

\section{Abbreviations}

HRQoL: health-related quality of life; EQ-5D-5L: EuroQoL-5 Dimension-5 levels; EQ-VAS: EuroQol-visual analogue scales; ANOVA: oneway analysis of variance; IDF: International Diabetes Federation; NGT: normal glucose tolerance; DM: diabetes mellitus; ADA: American Diabetes Association; HbA1C: Hemoglobin A1C; FPG: Fasting Plasma Glucose; PG: plasma glucose; OGTT: oral glucose tolerance test; SRS: simple random sampling; ANOVA: analysis of variance; PSM: propensity score matching.

\section{Declarations}

\section{Ethics approval and consent to participate}

This study was received ethical approval by China Ethics Committee of Registering Clinical Trials (protocol number: ChiECRCT20150048). Informed consent was obtained from all patients for being included in the study.

\section{Consent for Publication}

Not applicable.

\section{Availability of data and material}

The datasets generated and/or analysed during the current study are not publicly available but are available from the corresponding author on reasonable request.

\section{Competing interests}

No potential conflicts of interest relevant to this article were reported.

\section{Funding}

No funding was obtained for this study.

\section{Authors' contribution}


NY contributed to research design, analysis/interpretation of data, and wrote manuscript. EWL contributed to acquisition of data, interpretation of data and revised the manuscript. SF and JC contributed to acquisition of data, analysis/interpretation of data, revised the manuscript. LZS contribution to statistics analysis and reviewed manuscript. MH contributed to research design, analysis/ interpretation of data, revised the manuscript critically. All authors read and approved the final manuscript.

\section{Acknowledgements}

The authors thank all team members and participants from Sichuan Province of China and Tulane University of USA.

\section{References}

1. International Diabetes Federation. IDF Diabetes Atlas 7th Edition (2015). https://www.idf.org/e-library/epidemiologyresearch/diabetes-atlas/13-diabetes-atlas-seventh-edition.html

2. Janssen MF, Lubetkin El, Sekhobo JP, et al. The use of the EQ-5D preference-based health status measure in adults with Type 2 diabetes mellitus. Diabet Med 2015;28(April):395-413.

3. Schunk, M., Reitmeir, P., Schipf, S., Volzke, H., Meisinger, C., Thorand, B., et al. Health-related quality of life in subjects with and without type 2 diabetes: pooled analysis of five population-based surveys in Germany. Diabetic Medicine 2012;29(May),646-53.

4. Sakamaki H, Lkeda S, Lkegami N, et al. Measurement of HRQL Using EQ-5D in patients with Type 2 Diabetes Mellitus in Japan. Value in Health, 2006;9(January): 47-53.

5. Association, American Diabetes. Standards of Medical Care in Diabetes-2013. Diabetes Care, 2013, 36(Supplement-1):S11-S66.

6. Tabák A G, Herder C, Rathmann W, et al. Prediabetes: a high-risk state for diabetes development. Lancet 2012; 379(9833):2279-90.

7. M. Benjamin, R. Valdez, L.S. Geiss, D.B. Rolka, K.M. Narayan. Estimated number of adults with prediabetes in the US in 2000: opportunities for prevention. Diabetes Care 2003; 26:645-49.

8. W. Dunstan, P.Z. Zimmet, T.A. Welborn, M.P. De Courten, A.J. Cameron, R.A. Sicree, et al., The rising prevalence of diabetes and impaired glucose tolerance: the Australian diabetes, obesity and lifestyle study, Diabetes Care 2002;25:829-34.

9. Glumer, T. Jorgensen, K. Borch-Johnsen. Prevalences of diabetes and impaired glucose regulation in a Danish population. Diabetes Care 2003;26:2335-40.

10. Phillip T. Prediabetes and Lifestyle Modification: Time to Prevent a Preventable Disease. The Permanente Journal, 2014.88-93.

11. Matthias Hunger, Rolf Holleet et al.Longitudinal changes in health-related quality of life in general tolerance, prediabetes and type 2 diabetes: results from the KORA S4/F4 cohort study.Qual Life Res 2014. 23:2515-20.

12. Wang L, Gao P, Zhang M, et al. Prevalence and Ethnic Pattern of Diabetes and Prediabetes in China in 2013. JAMA 2017.317: 251523.

13. Wild S, Roglic G, Green A, Sicree R, King H. Global prevalence of diabetes: estimates for the year 2000 and projections for 2030. Diabetes Care 2004;27(May):1047-53.

14. Pan XR, Yang WY, Li GW, Liu J. Prevalence of diabetes and its risk factors in China, 1994. Diabetes Care 1997;20:1664-9.

15. Wang W,McGreevey W,Fu ,et al. Type 2 Diabetes in China: a preventable economic burden, American Journal of Managed Care 2009; 15(September):593-601.

16. International Diabetes Federation. IDF Diabetes Atlas 3th Edition (2006). https://www.idf.org/e-library/epidemiologyresearch/diabetes-atlas/22-atlas-3rd-edition.html

17. You Lu, Ningjian Wang. Health-related quality of life in type-2 diabetes patients: a cross-sectional study in East China. BMC Endocrine Disorders 2017; 17:38 2-7.

18. National Bureau of Statistics. Statistical yearbook of the people's Republic of China 2016.

19. Daniel Collado Mateo, Miguel A. García Gordillo. Normative values of EQ-5D-5L for diabetes patients from Spain.Nutr Hosp 2015;32(Apri):1595-1602.

20. O'Shea, M. P, Teeling M , Bennett K. Comorbidity, health-related quality of life and self-care in type 2 diabetes: a cross-sectional study in an outpatient population. Irish Journal of Medical Science 2015;184(March):623-30.

21. Zhou Ting,Liu Guoen et al. EQ-5D scale of Chinese disease population quality of life evaluation system. Chinese Journal of Evidence-Based Medicine 2016;2:135-142.

Page $7 / 10$ 
22. Bo Shi,Ruan Danjie,et al. Chinese middle-aged men have a higher prevalence of diabetes and more cardiovascular risk factors of aggregation. Chinese Medical Association, the thirteenth National Conference on Endocrinology Conference Guide.2014

23. Zhang Yaoguang, Xu Lin et al. Health-related quality of life of Chinese residents. Journal of Medicine and Society 2013;26(June):82-84.

24. Xu Y, Wang LM, He J,et al.Prevalence and Control of Diabetes in Chinese Adults. The Journal of the American Medical Association 2013; 310(September): 948-59

25. Turner R, Holman R, Cull C, et al. Intensive blood-glucose control with sulphonylureas or insulin compared with conventional treatment and risk of complications in patients with type 2 diabetes. Lancet, 1998; 352(9131):837-853.

\section{Tables}

Table 1 Socio-demographic features of respondents grouped by glucose status 


\begin{tabular}{|c|c|c|c|c|}
\hline Variable & $\begin{array}{l}\text { Normal glycaemic } \\
\text { population } \\
(\mathrm{N}=403)\end{array}$ & $\begin{array}{l}\text { Prediabetics } \\
(\mathrm{N}=404)\end{array}$ & $\begin{array}{l}\text { Diabetics } \\
(\mathrm{N}=398)\end{array}$ & $P$ value \\
\hline Mean age [years, (SD)]* & $58.94(12.48)$ & $53.29(9.21)$ & $62.23(11.3)$ & $<0.001$ \\
\hline Male sex $[n(\%)]^{*}$ & $195 \square 48.39 \% \square$ & $246(60.89 \%)$ & $212(53.27 \%)$ & $<0.001$ \\
\hline $\mathrm{BMI}\left[\mathrm{kg} / \mathrm{m}^{2},(\mathrm{SD})\right]^{*}$ & $23.67(4.24)$ & $23.73(2.99)$ & $24.57(4.05)$ & 0.001 \\
\hline Cigarette smoking & & & & 0.653 \\
\hline occasionally & 30 & 37 & 20 & \\
\hline often & 96 & 100 & 117 & \\
\hline never & 277 & 267 & 261 & \\
\hline Number of Cigarettes smoked & & & & 0.269 \\
\hline none & 276 & 266 & 260 & \\
\hline less than 5 per day & 22 & 37 & 15 & \\
\hline 10 or less per day & 29 & 37 & 24 & \\
\hline $10-20$ per day & 47 & 37 & 46 & \\
\hline more than 20 per day & 29 & 27 & 53 & \\
\hline Alcohol Consumption* & & & & 0.002 \\
\hline occasionally & 80 & 120 & 71 & \\
\hline often & 49 & 43 & 55 & \\
\hline never & 274 & 241 & 272 & \\
\hline Amount of alcohol consumption & & & & 0.400 \\
\hline none & 273 & 241 & 272 & \\
\hline around $50 \mathrm{ml}$ per day & 69 & 130 & 53 & \\
\hline around $100 \mathrm{ml}$ per day & 35 & 22 & 28 & \\
\hline around $150 \mathrm{ml}$ per day & 8 & 6 & 12 & \\
\hline around $200 \mathrm{ml}$ per day & 18 & 5 & 33 & \\
\hline Education level* & & & & $<0.001$ \\
\hline primary and below & 132 & 27 & 134 & \\
\hline junior or high school & 164 & 106 & 124 & \\
\hline college graduated & 56 & 132 & 80 & \\
\hline master and above & 51 & 139 & 60 & \\
\hline Health insurance* & & & & $<0.001$ \\
\hline none & 8 & 2 & 5 & \\
\hline China's urban employee basic medical insurance & 137 & 347 & 151 & \\
\hline China's new rural cooperative medical system & 157 & 36 & 69 & \\
\hline China's medical insurance for urban residents & 94 & 19 & 78 & \\
\hline Other commercial insurance & 7 & 0 & 95 & \\
\hline Household income* & & & & $<0.001$ \\
\hline low & 85 & 8 & 50 & \\
\hline average & 178 & 80 & 157 & \\
\hline relatively high & 121 & 163 & 139 & \\
\hline high & 19 & 153 & 52 & \\
\hline Sleep status & & & & 0.214 \\
\hline very poor & 31 & 13 & 12 & \\
\hline poor & 87 & 75 & 106 & \\
\hline general & 131 & 167 & 113 & \\
\hline good & 144 & 117 & 147 & \\
\hline very good & 10 & 32 & 20 & \\
\hline Family history of diabetes* & & & & $<0.001$ \\
\hline none & 351 & 311 & 269 & \\
\hline yes & 52 & 93 & 129 & \\
\hline
\end{tabular}

* - Difference was statistically significant.

Table 2 Blood glucose status of diabetics and pre-diabetics 


\begin{tabular}{lrll}
\hline \multicolumn{4}{c}{$\mathrm{HbA} 1 \mathrm{c}(\% \square \mathrm{FPG}(\mathrm{mmol} / \mathrm{L})$} \\
& $\mathrm{x} \pm \mathrm{SD}$ & $\mathrm{x} \pm \mathrm{SD}$ & $\mathrm{x} \pm \mathrm{SD}$ \\
\hline diabetics & $7.56 \pm 2.00$ & $8.16 \pm 2.98$ & $11.37 \pm 4.26$ \\
prediabetics & $5.93 \pm 0.31$ & $6.35 \pm 0.73$ & $9.17 \pm 1.73$ \\
\hline
\end{tabular}

Table 3 The composition of complications in three groups

\begin{tabular}{llllllll}
\hline & \multicolumn{3}{c}{ Normal glycaemic } & \multicolumn{2}{c}{ Pre-diabetics } & \multicolumn{2}{c}{ Diabetics } \\
\cline { 2 - 8 } & \multicolumn{2}{c}{ number constituent ratio number constituent ratio number constituent ratio } \\
\hline Circulatory system diseases & 102 & $25.31 \%$ & 94 & $23.27 \%$ & 152 & $38.19 \%$ \\
Nutritional metabolic diseases & 42 & $10.42 \%$ & 90 & $22.28 \%$ & 125 & $31.41 \%$ \\
Other diseases & 13 & $3.23 \%$ & 11 & $2.72 \%$ & 125 & $31.41 \%$ \\
Digestive system diseases & 10 & $2.48 \%$ & 20 & $4.95 \%$ & 33 & $8.29 \%$ \\
Urinary system diseases & 5 & $1.24 \%$ & 4 & $0.99 \%$ & 16 & $4.02 \%$ \\
Hematological Diseases & 6 & $1.49 \%$ & 5 & $1.24 \%$ & 11 & $2.76 \%$ \\
Endocrine system diseases & 9 & $2.23 \%$ & 5 & $1.24 \%$ & 5 & $1.26 \%$ \\
Respiratory diseases & 10 & $2.48 \%$ & 3 & $0.74 \%$ & 2 & $0.50 \%$ \\
Nervous system diseases & 1 & $0.25 \%$ & 0 & $0.00 \%$ & 2 & $0.50 \%$ \\
\hline
\end{tabular}

Table 4 Percentage of self-rated problematic on five dimensions

\begin{tabular}{llll}
\hline Dimension & \multicolumn{3}{l}{ Normal glycaemic Prediabetes Diabetes } \\
\hline mobility(\%) & 13.15 & 5.94 & 16.33 \\
\hline self care(\%) & 2.48 & 0.99 & 3.02 \\
\hline usual activities(\%) & 7.94 & 3.47 & 11.81 \\
\hline pain/discomfort(\%) & 51.12 & 37.13 & 56.78 \\
\hline anxiety/depression(\%) 41.94 & 27.97 & 44.72 \\
\hline
\end{tabular}

Table 5 The quality of life of the three groups

\begin{tabular}{|c|c|c|c|}
\hline \multirow[t]{2}{*}{ Variable } & \multicolumn{2}{|c|}{ Normal glycaemic Prediabetes } & \multirow{2}{*}{$\begin{array}{l}\text { Diabetes } \\
\mathrm{X}(\mathrm{SD}) \\
\end{array}$} \\
\hline & $X(S D)$ & $X(S D)$ & \\
\hline EQ-VAS scores & 73.76(14.06) & $77.45(9.18)$ & $68.34(14.27)$ \\
\hline EQ-Index(China-5 & $0.901(0.120)$ & $0.948(0.736)$ & $0.897(0.113)$ \\
\hline
\end{tabular}

Table 6 EQ-VAS and EQ-Index of three group before and after adjustment and matching

\begin{tabular}{|c|c|c|c|c|c|c|}
\hline & \multicolumn{2}{|c|}{ Normal glycaemic } & \multicolumn{2}{|c|}{ Prediabetes } & \multicolumn{2}{|l|}{ Diabetes } \\
\hline & EQ-Index & EQ-VAS & EQ-Index & EQ-VAS & EQ-Index & EQ-VAS \\
\hline \multicolumn{7}{|c|}{ Before adjustment $0.90100 .889,0913 \square 73.76 \square 72.39,75.14 \square 0.948 \square 0.940,0.955 \square 77.45 \square 76.56,78.35 \square 0.897 \square 0.886,0.908$} \\
\hline After adjustment & 0.91010 .9 & 74.7807 & $0.926 \square 0.91$ & 7075.49074 & $100.910 \square 0.9$ & 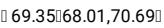 \\
\hline After matching & 0.86600 .8 & 9073.7107 & $\square 0.898 \square 0.87$ & $1075.71(73$ & 1) $0.846 \square 0.8$ & $66.20(70.24,73.54)$ \\
\hline
\end{tabular}

